\title{
Caracterização dos candidatos e dos selecionados da pós-graduação em educação da UFBA à luz da seletividade socioeducativa nacional
}

RESUMO: Este trabalho resulta de pesquisa voltada à configuração dos perfis dos candidatos e dos selecionados dos cursos de Mestrado e Doutorado da Faculdade de Educação da Universidade Federal da Bahia. A análise é estruturada no âmbito sócio-antropológico e, além de buscar oferecer dados e reflexões que interessam às funções acadêmicas e administrativas da Instituição, salienta as condições de seletividade social, que aguçada no Brasil, organiza um sistema educacional impresso na desigualdade social e que auxilia a sua renovação.

PALAVRAS-CHAVE: Pós-graduação - Seleção. Universidade Federal da Bahia - Faculdade de Educação - Pós-graduação.

O texto em apresentação resulta de pesquisa desenvolvida no Programa de Pós-Graduação em Educação da Faculdade de Educação da Universidade Federal da Bahia (PPGEDU-UFBA), em 2004, procurando caracterizar os inscritos nos seus concursos de Mestrado e de Doutorado, conferindo-lhes perfis e demandas reflexos das dinâmicas sociais contemporâneas. O trabalho voltase à organização e análise de informações que subsidiem a elaboração do Relatório anual da Unidade, em função dos requisitos acadêmico-administrativos da Instituição, mas vem também auxiliando a reflexão sobre a formação de educadores, desde 2001. Esses, dentre outros atributos, devem pensar as dinâmicas educativas, além de produzir e repassar conhecimento para os que atuam no sistema escolar, que, como é sabido, ainda não logrou instaurar-se solidamente, garantindo a formação das novas gerações com a eficiência preconizada e necessária.

Tendo como núcleo as relações entre educação, sociedade e práxis pedagógica, o PPGEDU reafirma o sentido e a responsabilidade das universidades públicas para com a comunidade, direcionando-se à promoção da melhoria do ensino. E, conferindo a expressão das desigualdades que estruturam a sociedade brasileira, especificamente, a baiana, busca subsidiar processos de constituição de sujeitos sociais transformadores. Exatamente por se tratar de um programa de uma universidade pública, apresenta
Fernanda Ma. Gonçalves Almeida

Pesquisadora da Pós-Graduação da FACED/UFBA

Professora Titular da UCSal

fga@ufba.br 
uma composição transdisciplinar, em virtude de referenciar-se na complexidade da vida social. Assim, necessariamente, é dinâmico e aberto ao debate. Coerentemente com tais propósitos, constrói e difunde reflexões, propiciadoras de ajustes e das mudanças requeridas, inclusive em termos das suas estruturas. Desta forma, além das finalidades já apontadas, este texto também é produzido no sentido de registrar o processo reflexivo, compor a memória institucional, facilitando a auto-avaliação que lhe deve ser garantida.

Visando esclarecer o sentido teórico-político deste trabalho, alguns paradigmas estão, sinteticamente, apresentados na introdução. Nela, também se descreve os passos dados para configurar a experiência anterior dos demandantes, sobretudo acadêmica, além de traços pessoais, considerados importantes à reconstituição das oportunidades sociopolíticas e culturais de permanência no sistema educativo. Tais atributos permitem aferir razões da busca por maior qualificação, que, se traduzem o anseio por aprimoramento acadêmico, também refletem as contínuas pressões do mercado atual, cujas crescentes exigências confirmam o papel da educação na promoção e justificativa da ampliada seletividade social. Se a III Revolução Industrial, estabelecida na década de setenta, instaura globalizantes e reduzidas definições de inserção produtiva, não se pode estranhar sua agudização, numa região periférica subordinada às grandes corporações.

Embora a tônica desta análise busque contribuir para o desenvolvimento das já referidas responsabilidades institucionais, pensa-se que não é demais trabalhar as informações colhidas também a partir de categorias analíticas político-sociais, na medida em que a Escola é, certamente, um espaço de exercício político abrangente e multiplicador. E, num país estruturado pela desigualdade, a educação desempenha papel nuclear à aceitação dos limites sociais. Daí o necessário estabelecimento da relação educação, sociedade e práxis pedagógica como área de concentração desta Pós-Graduação. Assim, também é elemento de instigação deste estudo ampliar a possibilidade de contribuir ao avanço das discussões voltadas às transformações sociais já enunciadas.

Como se sabe, perspectivas sociológicas tradicionais atribuíam à educação grandes responsabilidades junto com a distribuição dos bens sociais, disponibilizados pelo desenvolvimento. 
Porém, se esse truísmo prevaleceu durante décadas, a partir dos anos sessenta, outras linhas de reflexão, sobretudo instauradas por Bourdieu (1992; 1999), vêm procurando desmistificar tais modelos, ao apontar um outro sentido - e mesmo oposto - ao difundido poder da educação; ou seja, se ao sistema educativo cabe a formação para o trabalho, além de ser fundamental no processo integrador das novas gerações, não o faz - como é propagado costumeiramente - sem seletividade. Pelo contrário, tem intensa participação na dinâmica de perpetuação, justificativa e mesmo de aprofundamento das desigualdades sociais.

Todavia, linhas que compunham o primeiro tipo de reflexão - e que já se suponha fora dos debates - retornam à cena, pois são fortalecidos pressupostos liberais, refletindo o retorno da Economia ao núcleo do controle societário. Se, na maior parte do século XX, o maior peso dessa responsabilidade coube ao Estado, valendo-se, sobretudo, dos institutos de Bem-Estar Social, mudanças nos níveis de acumulação econômica, revigorada pelo terceiro estágio de tecnologia industrial e pelos novos limites geográficos do mercado, fazem voltar ao pilar econômico a primazia da ordem social. Isto reedita "discursos científicos" referenciadores de ideologia, mesmo que oferecidos por teorias, que se pensava absoletas - além de obscurantistas - como a do Capital Humano, defendidas por autores do porte de Schultz (1973).

Embora a dimensão deste trabalho dispense maiores elaborações teóricas, cabe situar categorias analíticas básicas, sobretudo oferecidas por Bourdieu (1992; 1999) e Foucault (1977; 1979), vez que elucidam a continuada renovação da seletividade social. Sobretudo, deve-se compor paradigmas relativos à ideologia e à cultura, já que seus processos promovem a reprodução de posicionamentos societários e de capitais culturais, alimentados por sistemas simbólicos, produzidos social e culturalmente; e, tornando consensuais as diferenças, renovarem e justificarem a dominação entre classes.

Sendo o foco desta análise a dinâmica seletiva de candidatos à Pós-Graduação em Educação de uma universidade pública, em um estado onde as desigualdades socioeconômicas e culturais saltam aos olhos - em extensão, profundidade e capacidade de se reproduzirem - pensou-se ser adequada uma estruturação analítica capaz de permitir a extrapolação do conjunto de caracterizações básicas dos candidatos; ao the recompor o "perfil", ir um 
pouco além, buscando situá-los mais amplamente, seguindo as trilhas que a seletividade social estabelece no traçado do sistema educativo. Se as instituições que o compõem são participantes do processo socializador, transmissor do conhecimento e formador dos recursos humanos, seu lado ensombrado dissimula estratégias e exercícios disciplinadores, impeditivos do acesso coletivo a bens socioculturais, dando-se, sobretudo, através da reserva do conhecimento para privilegiados, conseqüentemente da restrição da autonomia e da criatividade pessoais e grupais.

Grandes nomes da Sociologia da Educação nacional têm demonstrado a fragilidade argumentativa da referida teoria, inclusive pela percepção de que a expansão do sistema nacional - que, se até muito recentemente, alijava grandes contingentes populacionais - absorve precariamente segmentos da pobreza ainda hoje. Tratase de autores que denunciam precários resultados auferidos pela maior parte dos inseridos no Ensino Fundamental, no Médio, e, mais recentemente, mesmo no Superior. Indo além das aparências, revelam determinações eminentemente políticas, reconstruindo expressões sociais diferenciadoras e sustentando a seletividade. Entre outras funções que a escola pode cumprir é o prolongamento da escolaridade desqualificada, cujos "custos improdutivos", além de entrarem no ciclo econômico, servem de mecanismos de controle de oferta e demanda de emprego. (FRIGOTTO, 1984, p.157).

Auxiliando o processo de seletividade social, vigiando e punindo, a escola colabora com a justificação dos restritos espaços societários. Diploma eleitos, reprime e elimina muitos, ao tempo em que culpabiliza os parcial ou absolutamente excluídos, pela escassez de oportunidades. Controlando o acesso ao conhecimento e aos estatutos burocráticos referenciadores, reforça a separação entre pensantes e executantes, principais marcos sociais de diferenciação, distinguindo-os nos espaços societários. Com tais mecanismos, alija muitos dos acervos culturais construídos ao longo da experiência humana, restringindo-lhes o pertencimento comunitário, já que o trabalho educativo é o ato de produzir, direta e intencionalmente, em cada indivíduo singular, a humanidade que é produzida histórica e coletivamente pelo conjunto dos homens. (SAVIANI, 2003, p.13).

Sobre o processo educativo, os discursos oficiais emitem "verdades". Nestas, o arrazoado ultrapassa as afirmações frágeis, sustentando-se em místicas técnico-científicas, que elaboram o discurso 
competente. (CHAUÍ, 2000). Se os quantitativos de inseridos permitem otimismo, o ensino permanece precário em termos qualitativos, não garantindo os níveis que representa. Pelo Censo educacional de 2000, 84.30\% dos maiores de 5 anos estão alfabetizados. À primeira vista, seria um grande avanço, se refletisse condições básicas de comunicação e expressão - pilares da integração social e da inserção produtiva. É verdade que, contemporaneamente, a escola acolhe maiores contingentes. Contudo, rapidamente, "dispensa" a maioria, sem lhe garantir base à formação sociopolítica e à participação produtiva. Sua ineficiência é "transferida" aos estudantes, reproduzindo e justificando a desigualdade que organiza o País. O fato é ainda mais válido no Nordeste, onde o correspondente alfabetizado é menor: $72.81 \%$. Essa é a região onde a qualidade do ensino está mais comprometida. (IBGE, 2003).

Assim, a dimensão dos "alfabetizados" captada pelos censos funcionaria mais como mascaradora que reveladora, pois obtêmse a informação sobre alfabetização mediante pergunta aos questionados se são capazes "de ler ou escrever um bilhete simples [...]" no idioma que conhecem (IBGE, 2003), o que não, necessariamente, traduziria a real condição. Uma vez que os estigmas de semi-analfabetismo ou de analfabetismo constrangem, a tendência é o informante negá-la ou atenuá-la. Embora seja indiscutível a importância dos censos na caracterização populacional, a pesquisa quantitativa não é suficiente para retratar sua condição educativa, vez que dispensa informações substanciais, tornandoa, certamente, ainda muito distante da idealizada e insuficiente para o reconhecimento da realidade.

Todavia, se tais limites são nítidos, não impedem a aferição da seletividade educativa. Neste sentido, pode-se constatá-la, por exemplo, a partir de comparações entre os níveis educativos. Do total dos brasileiros alfabetizados, 3,64\% são graduados. São apenas $0,20 \%$ os mestres e doutores. Se esses números expressam clara diferenciação, o que dizer dos seus correspondentes nordestinos: 1,85\% e 0,09\%? (IBGE, 2003). E sempre convém lembrar o grau de responsabilidade dos que compõem os altos patamares educacionais, frente à necessidade de mudança das condições de formação dos amplos estratos societários mais baixos. Sobretudo, isto é pertinente àqueles que desfrutam dos serviços de uma universidade pública. 
Assim, abordar a condição da seletividade socioeducativa não foge às diretrizes das análises dos perfis dos demandantes de uma pós-graduação em educação. Este espaço é lócus ideal para refletir sobre as estratégias que delimitam o acesso ao conhecimento e aos seus certificados, vez que é nele que se formam os que atuam na produção de informações e no seu repasse aos novos docentes. Dessa forma, além das já anunciadas finalidades, com este estudo espera-se estar contribuindo à ampliação das reflexões sobre a formação dos que se propõem a pensar e atuar no preparo profissional dos que se direcionam à formação básica das crianças e jovens.

À construção analítica, criou-se o instrumento básico de coleta de informações, que é a Ficha de Inscrição. Nela existe o campo para a fotografia do candidato, principal fonte à sua caracterização étnica. Sobre isto, mesmo atentando à complexidade da questão e à estreita segurança conceitual, considera-se importante reproduzir os modelos censitários: branco, negro, pardo, pois podem fornecer indicações sociopolíticas do universo demandante. O preenchimento dos espaços relativos aos Dados Pessoais oferece elementos gerais à caracterização, sobretudo relativos a gênero, idade, naturalidade, nível de escolaridade, tipologia do curso anteriormente prestado e da respectiva instituição, além da condição atualizada de atividade profissional. Essas são informações cruciais à reconstituição dos perfis dos demandantes.

O preenchimento da ficha formaliza a inscrição. Em 2004, embora totalizando 635 inscrições, 15 não foram homologadas, por carecerem da documentação exigida ou por terem descumprido o prazo estabelecido. Assim, a pesquisa foi composta por um universo de 620 candidaturas, correspondentes, contudo, a 619 sujeitos, na medida em que um deles se inscreveu duas vezes: concorreu para o Mestrado e para o Doutorado. A organização das informações implicou na segunda etapa do processo, seguida da construção das categorias analíticas e de sua tabulação. Tais momentos desembocam na atividade analítica, promovida a partir da leitura das seguintes categorizações:

configuração das inscrições e das matrículas, no quadriênio 2001-2004;

candidatos e selecionados, por nível da Pós-Graduação; 2004; candidatos e selecionados pelas Linhas de Pesquisa; por ní- 
vel; 2004;

candidatos e selecionados por região de origem; por nível; 2004;

candidatos e selecionados por faixa etária; por nível;2004;

candidatos e selecionados por gênero; por nível; 2004;

condição de exercício docente dos candidatos e selecionados; por nível;2004;

tipologia da instituição de origem dos candidatos e selecionados; por nível; 2004;

tipologia da área cursada pelos candidatos e selecionados; por nível; 2004;

condição étnica dos candidatos e dos selecionados; por nível; 2004;

Esclarece-se que se fez agrupamentos por afinidade dos cursos anteriores, evitando-se desdobramentos que dificultariam a leitura. Por exemplo: dos 310 inscritos como concluintes de Educação, 90 eram mestres em Educação; 178 eram pedagogos; 39 graduados em Educação Física; e 01 em Educação Ambiental. Todos compuseram o grupo de educação, por entender-se que, apesar das diferenças nos níveis ou focos específicos, o núcleo formativo é comum. Outra observação pertinente é relativa à classificação étnica, que é obtida diferentemente dos métodos do IBGE, pois não se questiona o pesquisado sobre sua etnia, apenas se confere a "cor" e traços fisionômicos nas fotografias. Como se antecipa, mesmo reconhecendo como procedentes os questionamentos sobre categorizações étnicas e, sobretudo, "raciais", considera-se oportunas tais informações, já que as dinâmicas de seleção social são fundamentais à definição das oportunidades educativas; e sabese que as configurações étnicas pesam nas definições de espaços sociais e na construção das identidades; principalmente entre povos colonizados (HALL, 2003) e que viveram processos escravocratas.

Algumas das categorias construídas são desdobradas, conferindo-se isoladamente os candidatos por cada um dos dois níveis da Pós-Graduação, a fim de se considerar a diferenciação entre os dois grupos, sobretudo no que se refere à idade, ao nível de escolaridade e à experiência profissional. Também se desdobram algumas dessas tipologias, segundo o resultado da seleção, procurando estabelecer o contraste entre selecionados e não selecio- 
nados. Finalmente, à construção analítica, buscou-se outros subsídios, permitindo conferir tais perfis no universo mais amplo baiano e brasileiro. Cabe destacar dados censitários e amostrais do IBGE, principalmente relativos à educação. Nesse âmbito, esclarece-se que algumas das tabelas da página do IBGE utilizadas continham equívocos em suas totalizações. Porém, foi possível neutralizá-los, através da simples recomposição das somas das suas parcelas.

A história institucional informa que a UFBA cria o Mestrado em Educação em 1972. O Doutorado é instaurado vinte anos depois, refletindo o avanço do projeto docente, num estado em que as condições educativas são tradicionalmente precárias e seletivas. Consciente de suas atribuições, o PPGEDU promove análises sobre suas próprias práticas, inclusive avaliando as demandas que 1he vêm e sua capacidade para atendê-las. Dentre estas, nos últimos quatro anos, organiza o estudo do perfil dos candidatos. As informações expostas a seguir dimensionam as inscrições nos concursos e as de matrículas de 2004, analisando as incidências, além de, em alguns casos, compará-las com as tendências anteriores, como se vê no Gráfico 1.

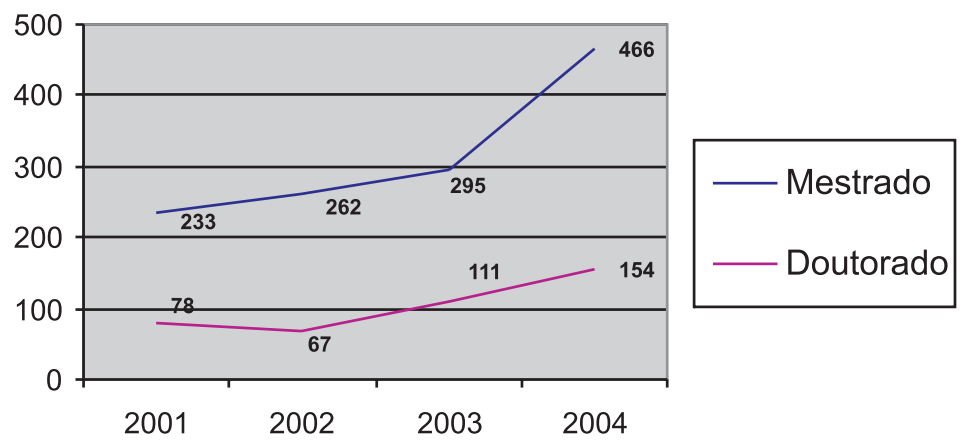

Gráfico 1 - Dinâmica das inscrições nos concursos; quadriênio 2001-2004; por nível

Fonte: PPGEDU, 2004

Elaboração: Wanessa Malaquias e Cleverson Suzart.

Na Figura, vê-se que a procura pelos cursos apresenta-se crescente, sobretudo significativa em relação ao último ano, quando expressa o maior distanciamento verificado entre as etapas do período e dobrando a incidência de inscrições em relação ao marco 
original, representando 99,4\%. Por outro lado, o traçado das matrículas efetivadas revela a condição seletiva dos concursos ou mesmo os limites institucionais para o atendimento da demanda. Se esta, ao longo dos quatro anos, duplicou, o índice de matrículas cresceu apenas 25,0\%, como está explícito no Gráfico 2.

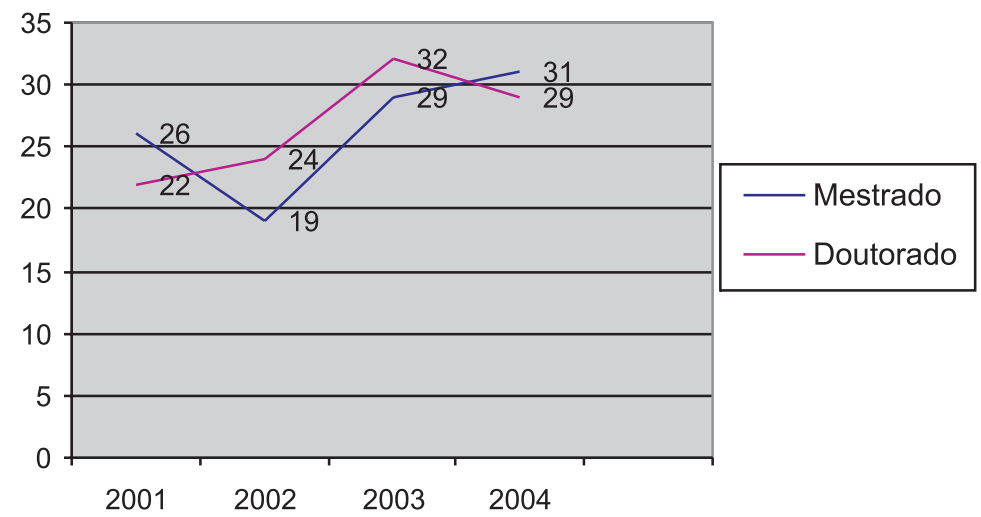

Gráfico 2 - Dinâmica das matrículas nos cursos; quadriênio 2001-2004; por nível Fonte: PPGEDU, 2004

Elaboração: Wanessa Malaquias e Cleverson Suzart.

Em termos de inscrições por curso, permanece a tendência da maior concentração no Mestrado. Em 2004, houve 620 inscrições, sendo que os pleiteantes ao primeiro nível significaram 465 (75,0\%) do total. Contudo, se a concorrência entre os candidatos aos dois cursos expressa quantidades tão díspares, o resultado da seleção apresenta absorção equilibrada: 51,7\% e 48,3\%, respectivamente para o Mestrado e para o Doutorado.

Nesse ano, as demandas distribuem-se pelas Linhas de Pesquisa institucionalizadas, imprimindo maior incidência na de Currículo, Tecnologias de Informação e Comunicação, com 40,3\% das candidaturas. Essa linha direciona-se aos estudos das "relações entre currículo, trabalho, conhecimento, cultura e comunicação nos seus aspectos epistemológicos, históricos, sócio-políticos, institucionais e psicopedagógicos, tendo a prática educacional como base instituinte". (UFBA, 2004, grifo nosso).

Certamente, tal preferência advém do fato da prática educacional não expressar apenas um núcleo formativo docente, ao redor do qual gravitam tendências de reprodução da formação educativa; mas, também, por estabelecer vetores conectados à di- 
nâmica societária em âmbitos significativos da estruturação da vida coletiva, como o do trabalho e da produção de conhecimento.

Assim, essa linha abre oportunidades em campos amplos e de importantes espectros, incluindo desde grandes focos (filosóficos, psicopedagógicos, socioantropológicos, políticos, históricos) até os mais específicos, como os institucionais, tornando compreensível a incidência da procura. Destaca-se, ainda, que a linha apóia recentes temáticas da comunicação, incluindo novas tecnologias educacionais, e que, considerando a importância que essas vêm tendo nas últimas décadas, estabelecem uma maior exigência de produção de conhecimento e divulgação de novos usos pedagógicos de instrumentalização. Finalmente, observa-se que, até meados de 2004, ainda cabiam nesse núcleo de estudos as temáticas relativas à Educação Física, ao Esporte e ao Lazer, que, por virem apresentando crescentes e diversificados interesses, ao final do ano se constituíram numa nova linha, ganhando autonomia e independência já para o concurso seguinte.

A segunda linha mais procurada é a de Filosofia, Linguagem e Práxis Pedagógica, abrangendo 32,9\% das inscrições, e onde são destacadas "as relações entre atos educativos e seus pressupostos lingüísticos e filosóficos" (UFBA, 2004), cujas subáreas incluem a epistemologia e práxis educativas, educação e ludicidade, proposições e práticas de educação inclusiva, Filosofia, Educação e gênero.

Finalmente, a última linha, Políticas e Gestão da Educação, é procurada por $26,8 \%$ dos inscritos. Estes buscam aprofundamento em estudos e análises dos processos e gestões da educação, em suas diferentes modalidades; voltam-se também às politicas públicas em todas as dimensões; e ainda às relações dessas duas esferas com as demandas ou reações frente ao sistema educacional, promovidas pelas mobilizações societárias.

As informações seguintes indicam a distribuição dos selecionados por Linha, expressando contraste em relação às incidências anteriores. A Linha de Filosofia é a que acolhe mais estudantes: 40,0\% do universo, enquanto cabem 33,3\% à de Currículo e 26,7\% à de Gestão. Certamente, isto decorre de que, nos anos imediatamente anteriores ao concurso 2004, o maior número de matrículas deu-se na Linha de Currículo, sobrecarregando o seu corpo docente, conforme se pode observar nos respectivos relatórios. (ALMEIDA, 2002, ALMEIDA; SUZART, 2002, ALMEIDA; SILVA, 2003). Ocupando-se com muitas orientações das seleções passa- 
das, os professores têm menor disponibilidade para novas orientações.

Em referência à Origem dos Candidatos, já na análise de 2003 (ALMEIDA; SILVA, 2003) se chama a atenção para a mudança no quadro da naturalidade dos demandantes. Se este Programa foi pensado para, prioritariamente, atender necessidades de formação docente e científica da Bahia, dos demais estados nordestinos e dos nortistas, nos últimos anos constata-se alterações, pois a procura por parte de candidatos do Sul e Sudeste intensificou-se, embora a maior expressão continue sendo de baianos - em 2004, da ordem de 70,0\%. Os pleiteantes de outros estados nordestinos e dos nortistas significam, respectivamente, 9,5\% e 0,6\%, enquanto os do Sul e Sudeste corresponderam a 15,8\% do total. Este último índice confirma a tendência salientada - e mesmo revela ampliação - se comparado ao de 2003: 14.8\%. (ALMEIDA; SILVA, 2003).

Naturalmente, tal incidência reflete-se na composição final dos selecionados. Nesta, os baianos representam 70,0\% dos matriculados; outros nordestinos são 7,0\%; os do Sul e do Sudeste 10,0\%. São inexpressivos os provenientes do Centro-Oeste e de outros países, cada um dos grupos expressando 2,0\% do total. Finalmente, confirmando o já expresso no processo seletivo de 2003 (ALMEIDA; SILVA, 2003), não há registro de nortistas.

É possível que a crescente procura pelo Programa decorra do reconhecimento de sua qualidade frente à CAPES, que, desde o triênio 1998-2000, atribui-lhe Classificação 4. Contudo, além desse fato, o fenômeno pode estar ligado aos limites do atendimento local dos candidatos, provocando vias de fuga, principalmente depois que a Terceira Revolução Industrial, instaurando novos modelos produtivos, reforça os padrões competitivos dos traba1hadores, restringindo fronteiras e expandindo a órbita de seus deslocamentos. Por outro lado, embora a imagem mais comum da Bahia seja de um estado repulsor de população - mormente de mão-de-obra rural - concretamente, este estado sempre foi, também, um pólo de atração, principalmente para outros trabalhadores nordestinos. Ainda, nos últimos trinta anos, tem havido fluxos significativos de pessoas vindas do Sul e do Sudeste, inclusive de maior escolaridade, em face da expansão laborativa nas indústrias e nos serviços.

Nesse sentido, dados do IBGE (2003) atestam que, entre 1998 e 2003, 742.729 pessoas de outros estados passaram residir na Bahia. 
Sobretudo, Salvador tem exercitado grande atração a estratos populacionais de maior bagagem sociocultural, em decorrência desses novos campos produtivos, além da maior divulgação de suas matrizes culturais e riqueza estética. Se antes prevalecia a imagem do atraso, a figuração construída nos últimos anos é de que, aqui, se dá o desenvolvimento, ampliando as oportunidades de trabalho, ao tempo em que se dispõe de um ambiente social mais sereno e alegre.

Relativamente às condições etárias, como se constatara nos anos anteriores, há um rejuvenescimento, se se compara aos quadros das primeiras etapas do PPGEDU. Isto, naturalmente, resultava de históricas e reprimidas demandas, imprimindo maior pressão ao atendimento aos que já exercitavam a docência, inclusive no próprio âmbito da UFBA. Posteriormente, atendidas essas, amplia-se o espaço às novas gerações. Mais proximamente, outros fatores intervêm, entre estes os relativos à reestruturação produtiva. Neste sentido, tem sido palpável a maior afluência daqueles que - mesmo já estando no mercado e na área acadêmica - buscam atualizarem-se em termos técnico-científicos, pedagógicos ou metodológicos.

Também há maior demanda dos mais jovens, buscando inserir-se no mercado, que, inclusive, vale-se de certificados para justificar sua seletividade. Muitos postergam a entrada no processo produtivo, pois se o movimento do capital tem-se caracterizado pela restrição dos empregos, também - e mesmo por isto - renova requisições na formação, mormente relativas ao uso de novos instrumentos e técnicas e de relacionamento no espaço laboral. E, ainda por força disso, se a atual dinâmica do capital dá-se no sentido de estreitar os postos de trabalho, em campos específicos - como o educacional - o mercado expande-se, e exige formação mais aprofundada. É pertinente analisar o fenômeno, pois, na Bahia, verifica-se grande aumento de cursos universitários, requerendo pessoal especializado. Como se verificou em 2003, em 2004 mais da metade dos que prestaram concurso para o Mestrado têm até 35 anos $(51,5 \%)$ e os maiores de 51 anos expressam 6,2\% do total. Para o nível mais alto - o Doutorado - a faixa etária mais densa é a de 36 a 40 anos, com 25,8\% das inscrições.

Ainda, a tais variáveis pode-se acrescer outra, que, embora não tenha poder isolado para definir resultados, seria capaz de influenciá-lo. Trata-se de que, embora do ponto de vista legal não 
haja esteio, difusamente a questão etária pode interferir, favorecendo aos mais novos, vez que esses, potencialmente, oferecem maior possibilidade de vida útil ao sistema. Este panorama também tem sido reforçado em virtude de que, nos últimos anos, registrou-se forte movimento de aposentadorias universitárias.

Assim, é possível que, mesmo mudando as composições dos grupos concorrentes à Pós-Graduação, os selecionados, sobretudo do primeiro nível, continuam apresentando perfil mais jovem, se comparado aos dos anos anteriores. A tendência não é tão forte com os do Doutorado, provavelmente em virtude das demandas anteriores ainda não terem sido supridas. Isto estaria indicado por repetidas tentativas efetuadas pelos mesmos candidatos, que seguem se inscrevendo ano a ano, e envelhecendo. Do total de inscritos que foram selecionados para o Mestrado, 64,5\% estão com menos de 35 anos. Em 2003, foram 51,8\%. Já os de 51 anos e mais foram 10,3\%; neste ano são 6,5\%. Os do Doutorado com menos de 40 anos são $48.3 \%$, mantendo a tendência de $2003(50,0 \%)$.

Em termos de gênero, não há grandes mudanças na demanda. As variáveis culturais continuam atuando, atraindo mais as mulheres às áreas educativas. Em 2004, essas representaram 71,1\% dos candidatos, mantendo a tendência histórica. Neste sentido, os índices de 2001, 2002 e 2003 foram de 69,7\%, 72,0\% e 70,0\%, respectivamente. Porém, entre os selecionados, a expressão feminina perde significação: as aprovadas são $65 \%$ do total. Poderse-ia considerar o crescimento da procura masculina como decorrente de mudanças socioculturais havidas nas últimas décadas, que, rompendo estereótipos, aproximam os dois gêneros no mercado de trabalho. Contudo, não seria incoerência complementar essa leitura com outras reflexões, explicando o fenômeno como uma das conseqüências da reorganização socioprodutiva, que, como já se salientou, acentua a concorrência entre trabalhadores, na luta pelos postos de trabalho.

Sobre a condição de exercício docente dos candidatos, também é mantida a dinâmica constatada nos anos anteriores, confirmando a maioria de não-docentes, 59,9\%. Contudo, as configurações nos dois níveis são muito desiguais; para o Mestrado, 74,9\% não são docentes; dos demais, apenas 3,0\% são professores desta Universidade. Já para o Doutorado há outra conformação: 85,1\% são docentes; destes 9,0\% atuam na UFBA. 
Seja pelos currículos, seja pela proximidade com as temáticas, os já professores têm maiores possibilidades de êxito. Assim, dos 60 selecionados, $31(51,7 \%)$ são docentes, sendo que $10 \%$ da UFBA e 41,7 de outras instituições. Este último índice é similar aos encontrados nos anos anteriores - a exemplo de 2003, quando 42,6\% dos selecionados atuavam em outras universidades - e confirma a importância da UFBA para a formação de quadros de outros estabelecimentos. Dos selecionados para o Mestrado, 11 (35,5\%) são professores. Desses, apenas 3 (9,7\%) são da UFBA. Entre os selecionados para o Doutorado, predominam os docentes: 20 (68,9\%) dos 29 selecionados. A tendência dos últimos anos da maioria dos docentes selecionados ser composta por professores de outras universidades, indica a pioneira formação dos profissionais da UFBA.

Outro aspecto a destacar diz respeito à condição institucional da formação anterior dos candidatos e dos selecionados. No primeiro grupo, 29,5\% tinham formação nesta Universidade. Uma das variáveis que mais deve interferir nesse quadro é, naturalmente, o local de origem do inscrito. Neste sentido, convém lembrar que a incidência dos soteropolitanos é 34,5\% do total e a maioria dos cursos da UFBA está nesta cidade. Por sua vez, 50\% dos selecionados tiveram formação anterior nesta Universidade. Isto é, principalmente, resultante do fato de que, se a UFBA já não é a maior universidade de Salvador e da Bahia, ainda é a mais importante e a que, reconhecidamente, oferece melhores formações.

Mesmo que o foco central desta Pós-Graduação seja em Educação e em Ciências Humanas, os demandantes advêm de áreas diversas. Dos 620 inscritos, exatamente a metade tem formação educativa. O segundo maior grupo vem das Ciências Humanas, com 155 (25\%) inscritos; de Letras provêm 60 (9,7\%); das Exatas e da Saúde vêm, respectivamente, 6,3\% e 5,2 \%; são das Artes 3,2\%. Este mosaico já se configura tradicionalmente e é algo que facilita o ambiente transdisciplinar.

Finalmente, como em 2002 e em 2003, quis-se averiguar a condição étnica de candidatos e dos selecionados, na medida em que um estudo desta natureza pode colaborar para o avanço das discussões sobre a seletividade socioeconômica e cultural - referência da desigualdade - e sua interferência no âmbito escolar. Se o fenômeno funda a brasilidade, ainda mais o faz na Bahia, onde, reconhecidamente, a população é predominantemente negra e parda. Neste sentido, registrou-se no relatório de 2003 que 
[...] embora a cultura conhecida como afro-baiana seja hegemônica, grandes grupos de seus representantes vivem em estado de extrema vulnerabilidade ou mesmo de exclusão, em decorrência da precariedade de envolvimento - ou mesmo afastamento - em relação ao sistema produtivo e de consumo, e de semi ou total afastamento relativamente às instituições de apoio relacional. (ALMEIDA; SILVA, 2003, p. 29-30)

Na sociedade moderna, a escola é um dos institutos mais importantes da rede de socialização, de formação para o traba1ho, além de ser a principal fonte transmissora de elementos culturais necessários à integração, ao pertencimento grupal e comunitário. Ao disponibilizar seus serviços de forma desigual, age em conjunção a outros mecanismos de reprodução social. Assim, não é estranho que as populações herdeiras dos traços socioeconômicos e étnicos dos subjugados do passado continuem a enfrentar restrições nas vias de acesso aos bens de sociabilidade e ao conhecimento. Conforme se pode verificar na próxima figura, cerca de metade dos candidatos está classificada como branca, embora - conforme já se salientou - os concursos se dêem numa cidade negra. Esta tendência tem-se mantido constante desde a aferição de 2001.

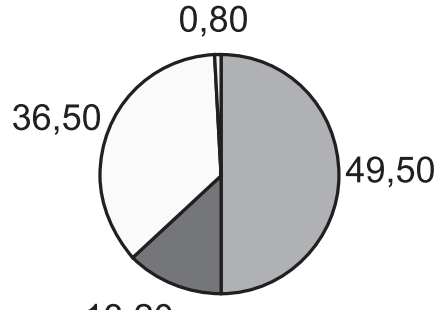

13,20

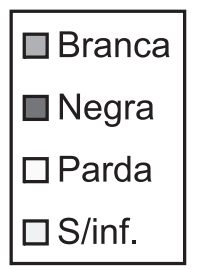

Gráfico 3 - Condição étnica dos Candidatos (\%)

Fonte: PPGEDU, 2004.

Elaboração: Wanessa Malaquias e Cleverson Suzart

Não obstante ser o negro o principal fundamento étnico de Salvador, o fenômeno não é peculiar a esta cidade, pelo contrário, transversaliza o território nacional, restringindo as oportunidades socioeconômicas e culturais dos que descendem dos 
escravizados. Se há uma seletividade social que restringe para poucos a educação universitária, pardos e, principalmente, negros com nível de graduação são inexpressivos. Dados censitários de 2000 (IBGE, 2003) revelam o distanciamento do acesso à educação, segundo a condição de "cor ou raça". Consoante Tabela 1.12, que cruza as variáveis escolaridade, cor e grupos de idade, do total dos que se declararam brancos na apuração do ano, 9,38\% detinham diploma universitário; na mesma condição estavam 2,26\% dos pardos e $2,03 \%$ dos pretos. A tendência é acentuada se são consideradas as mesmas proporções entre os correspondentes grupos étnicos nordestinos: 6,76\%, 2,02\% e 1,31\%, respectivamente (Tabela 2.2.12).
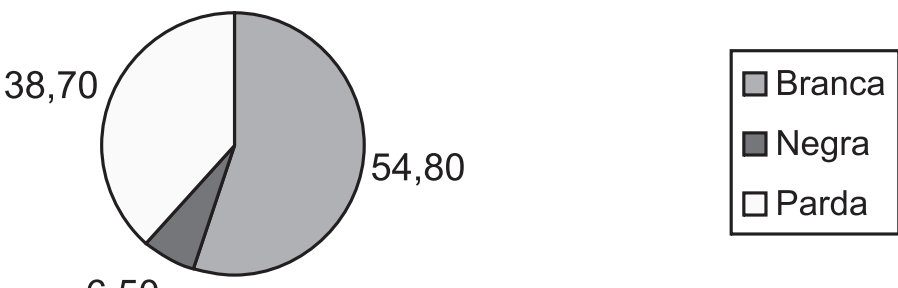

6,50

Gráfico 4 - Distribuição dos Selecionados, segundo a etnia; Mestrado (\%) Fonte: PPGEDU, 2004.

Elaboração: Wanessa Malaquias e Cleverson Suzart.

O acúmulo histórico de condicionantes elitizantes, naturalmente repercute no resultado do processo seletivo do Mestrado e, ainda, de forma mais acentuada no do Doutorado, conforme se pode constatar nos dois gráficos expostos. 

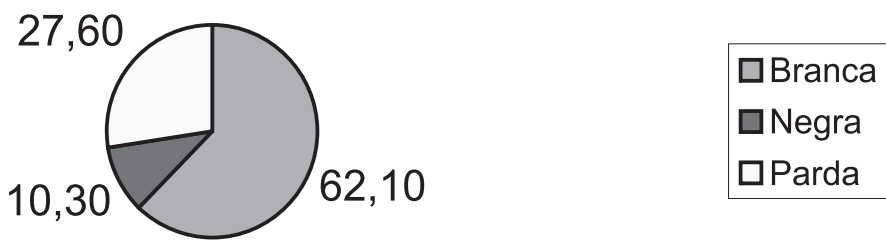

Gráfico 5 - Distribuição dos selecionados, segundo a etnia; Doutorado (\%)

Fonte: PPGEDU, 2004

Elaboração: Wanessa Malaquias e Cleverson Suzart.

Conforme se apresentou, a maior parte dos candidatos aos concursos de 2004 (75\%) se propunha ao curso de Mestrado, conseqüência das recentes tendências de expansão da graduação, mesmo que, como, também, se destaca, esse patamar de escolaridade ainda permaneça extremamente seletivo. Como seria esperado, foi mantida a predominância de baianos sobre outras naturalidades, embora continue a se acentuar a presença de candidatos do Sul e do Sudeste do Brasil, constituindo-se mais expressivamente que aquelas provenientes de outros estados do Nordeste e do Norte.

As faixas etárias mais jovens - abaixo de 35 anos - vêm confirmando sua prevalência nos últimos anos, expressando o atendimento anterior das demandas do pessoal mais velho, mas, certamente, também refletindo a maior pressão do mercado por qualificação, visto que os postos de trabalho estão mais restritos, em decorrência das novas características do processo produtivo.

Ainda cabe um outro destaque, relativo à questão de gênero. Se se reconhece como histórica a maior vocação feminina às formações educativas, nos últimos anos tem-se verificado ampliação da demanda masculina, provavelmente em virtude das quebras de preconceitos, bem como em decorrência dos novos modelos de inserção na produção, que provocam o retardo de participação no mercado de trabalho das novas gerações, ao mesmo tempo em que reforçam o discurso da competência.

Finalmente, pode-se promover algumas considerações finais. Inicialmente, e como já salientou em relatório do ano passado (ALMEIDA; SILVA, 2003), um dos poucos mercados que têm ampliando as oportunidades de inserção é, exatamente, o da educa- 
ção, em virtude das necessidades criadas em termos de reciclagem de conhecimento teórico-técnico e, sobretudo, instrumental. Mais que isto, contudo, a exigência de maiores patamares de ensino reflete a importância de se obscurecer as restrições das oportunidades de trabalho, que vêm - em todo o mundo - estendendo a cobrança por maior escolaridade e a dependência dos jovens às suas famílias de origem.

Diante do domínio do mercado no social, não há lugar para a ingenuidade de pensar que todos os que se candidatam à PósGraduação o fazem em virtude de "vocação" ou por compromisso acadêmico ou político. Se a Educação é um dos principais institutos sociais para o repasse de ideologias, ainda mais se espera dela em tempos neoliberais. Neste sentido, não só para cumprir as determinações das instâncias de controle do sistema de ensino universitário, há pertinência no empenho em buscar conhecer o perfil dos candidatos e dos selecionados nos concursos sob a responsabilidade deste PPGEDU.

Também cabe acentuar algumas instigações relativas a atribuições do sistema educativo, que são pouco nítidas, como sua importância na difusão do discurso oficial sobre a suposta democracia, sua colaboração à aceitação das desigualdades e mesmo da exclusão. Em artigo recente, Lígia M. Martins (2004, p. 54) indaga: "O que é educar? Quem é o homem que se educa? Educa-se em razão de quê?" Esta tem sido uma questão posta por muitos dos que se dedicam a pensar o processo educativo, a formular políticas públicas, a conduzir ações educacionais, na medida em que a importância e a responsabilidade da Educação são de interesse de toda a coletividade. A autora indica que respostas "prontas e certeiras" estão bastante disponibilizadas. De fato, são constantes nos discursos de todos os envolvidos, sobretudo em se tratando de educadores. Martins alerta, porém, que, por sua obviedade, os tratamentos dados à questão, geralmente, são mais capazes de obscurecer do que esclarecer. Recorrendo a Marx, reafirma a necessidade de perceber para além do real evidenciado.

Cabem as referências dessas últimas reflexões, embora não sejam inéditas, uma vez que podem reforçar o esteio deste trabalho, tanto no seu objetivo mais imediato - a caracterização dos sujeitos demandantes dos cursos desta Pós-Graduação - quanto também naquela proposição mais estendida, que deve ser constante para todos os que se dedicam a conferir - e mudar - as 
condições educacionais do País. Assim, um dos paradigmas que norteiam esta análise baseia-se na constatação de que, com o avançar da Idade Moderna, a educação escolar torna-se um dos institutos mais fundamentais para promover a integração social das novas gerações. Desdobrando-se tal reflexão, sabe-se também que, mais tarde - a partir da I Revolução Industrial - tem sido crescente sua importância nas definições de inserção no processo produtivo.

Coerentemente, durante muitos anos do Século XX constatou-se o peso dos atributos educacionais no auxílio da delimitação de condições de integração social e de inserção no mercado de trabalho. Todavia, as formulações que atribuem à educação papel definidor das formas de participação na produção - e mesmo para o estabelecimento de correspondentes patamares de renda - se tiveram algum espaço, hoje se encontram desgastadas, pela impossibilidade de representarem o real. Por isso, as perspectivas do Capital Humano e suas correlatas vinham perdendo espaço desde os anos sessenta. Mais recentemente, em tempos neoliberais, vêm ensaiando um retorno, certamente para auxiliar no cumprimento da tarefa política de obscurecer outras contradições, decorrentes do desenvolvimento do processo tecnológico e de acumulação do capital.

Tais tentativas logram pouco êxito, uma vez que o crescente dimensionamento dos "sem lugar" no espaço produtivo não mais pode passar despercebido, assim como se tornam cada vez mais visíveis as sempre menores extensões do Estado de Bem-Estar Social para reciclar ou para, definitivamente, amparar os que deixam de ser importantes à produção. O fenômeno é mundial e com feições ainda mais preocupantes nos países subdesenvolvidos, onde o desemprego é algo estrutural e fundante.

Os grupos dos "sem muitas perspectivas de trabalho", sobretudo, são compostos por jovens, mulheres e pelos mais escolarizados, estes vêm se apresentando num crescendo inquietador. A título de ilustração desse fenômeno no Brasil, são notáveis os dados obtidos pelas pesquisas do IBGE, que apontam que, em janeiro de 2003, 52,8\% dos desempregados eram mulheres; no janeiro seguinte, 54,4\%; no mesmo mês deste ano são 56,9\%. Naquilo que referencia a relação entre desemprego e níveis educacionais, a mesma fonte indica que os que têm, pelo menos, Ensino Médio concluído, representam 39,0\%,42,2\% e 46,2\% dos desem- 
pregados, respectivamente para as três datas referidas. (IBGE, 2005).

Diante desse cenário, pode-se refletir acerca da composição dos candidatos aos cursos desta Pós-Graduação e daquela menor que configura o grupo dos selecionados. Certamente, ambos são compostos por pessoas que conseguiram estar muito além da média educacional dos brasileiros, cabendo-lhes maior espaço de reflexão sobre o que fazer educativo do Brasil, inclusive para aqueles que não têm, previamente, experiência educativa, que, como foi apontado, constituem a maioria dos inscritos e quase a metade dos que lograram êxito na seleção.

A própria essência de uma Pós-Graduação em Educação, mais do que de outras áreas, permite o recebimento de estudantes provenientes de muitos espaços acadêmicos, sobretudo daqueles pedagógicos, das Humanas, e de Letras, compondo o núcleo básico das Humanidades. Se essa largueza estende a oportunidade das trocas entre docentes e discentes do Programa e, portanto, enseja o enriquecimento, exige renovações continuadas diante dos questionamentos suscitados no quotidiano. Certamente, daí advêm os maiores frutos já alcançados pelo PPGEDU e sua potencialidade em recriar-se.

Tal dinâmica, somada àquelas que são trazidas pelas questões educacionais de um país como o Brasil, ainda por propiciar o pleno acesso à escola e por garantir a qualidade do ensino, seguramente tem exigido esforços extras, aos quais o PPGEDU tem procurado responder, embora sozinho não tenha forças para reverter o extremado processo seletivo ainda em vigência na nossa sociedade. Nesse sentido, devem ser confirmadas suas condições político-sociais, capazes de intensificar as mobilizações em prol da educação para a cidadania.

Description of candidates and those selected for the postgraduate course in Education at Ufba given the national socio-educational selection policy

\footnotetext{
ABSTRACT: This article analyzes the results of a research about the profile of candidates and the selected ones to the post graduation program (master and doctorate degrees) at Faculdade de Educação of Universidade Federal da Bahia. The analysis is based on socioanthropological approach and it aims at finding data which will be useful for the institution in the academic and administrative areas. Such data shows how the selection process reflects the socially unfair Brazilian Education system.

KEY WORDS: Education. Posgraduation. Social selectivity. Social inequality.
} 
ALMEIDA, Fernanda Maria Gonçalves. Perfil dos candidatos ao Programa de Pós-Graduação da Faculdade de Educação da UFBA (2002). Salvador: Programa de Pós-Graduação em Educação, Faculdade de Educação, Universidade Federal da Bahia; 2002.

; SILVA, Marcela M. J. Perfil dos candidatos da Pós-Graduação da Faculdade de Educação da UFBA (2002). Salvador: Programa de Pós-Graduação em Educação, Faculdade de Educação, Universidade Federal da Bahia, 2003.

SUZART, Cleverson. Perfil dos candidatos da Pós-Graduação da FACED em 2001. Salvador: Programa de Pós-Graduação em Educação, Faculdade de Educação, Universidade Federal da Bahia, 2002.

BOURDIEU, Pierre. A economia das trocas simbólicas. São Pau1o: Perspectiva, 1999.

A reprodução. Rio de Janeiro: Francisco Alves, 1992.

CHAUİ, Marilena. O discurso competente. In:

Cultura e

democracia: o discurso competente e outras falas. São Paulo: Cortez, 2000. p.3-13.

FOUCAULT, Michel. Microfísica do poder. Rio de Janeiro: Graal, 1979 .

1977.

Vigiar e punir: nascimento da prisão. Petrópolis: Vozes,

FRIGOTTO, Gaudêncio. A produtividade da escola improdutiva: um (re) exame das relações entre educação e estrutura econômicosocial capitalista. São Paulo: Cortez, 1984.

HALL, Stuart. Da diáspora: identidades e mediações culturais. Belo Horizonte: Editora UFMG, 2003.

IBGE. Censo demográfico 2000: características da população e dos domicílios: resultados do universo. Rio de Janeiro, 2003. < http:// www.ibge.gov.br/home/estatistica/populacao/censo $2000 /$ default.shtm >. Acesso em: 28 fev. 2005. Acesso em: 28 fev. 2005.

Censo educacional, 2003. Rio de Janeiro, 2003. < http:// www.ibge.gov.br/home/estatistica/populaçao/censo2000/educaçao/ censo2000_educ.pdf > Acesso em: 28 fev. 2007.

IBGE. Pesquisa mensal de emprego: PME. Rio de Janeiro, 2005. Disponível em: <http://www.ibge.gov.br > Acesso em: 28 fev. 2005.

MARTINS, Lígia Márcia. Da formação humana em Marx à crítica da pedagogia das competências. In: DUARTE, Newton (Org.). Crítica ao fetichismo da individualidade. Campinas, SP: Autores Associados, 2004. p. 53-73. 
SAVIANI, Dermeval. Pedagogia histórico-crítica: primeiras aproximações. Campinas: Autores Associados; 2003.

SCHULTZ, Theodore W. O capital humano: investimentos em educação e pesquisa. Rio de Janeiro: Zahar, 1973.

UNIVERSIDADE FEDERAL DA BAHIA. Faculdade de Educação. FACED-PPGEDU: seleção 2004. Salvador, 2004. Folder. 